\title{
Pengolahan Limbah Cair Pembuatan Minuman Ringan Dengan Reaktor Semiaerobik, TCPS, Reaktor Anaerobic Dua Tahap
}

\author{
Hasti Suprihatin ${ }^{1}$ \\ ${ }^{1}$ Program Studi Teknik Lingkungan, Fakultas Teknik Sipil dan Perencanaan, Institut Teknologi Pembangunan \\ Surabaya Jalan Balongsari Praja V/1 Surabaya, Telp (031) 7406783
}

\begin{abstract}
The existing soft drink factory can produce liquid organic waste with a COD content starts from $6,000 \mathrm{mg} / \mathrm{l}$ to $15,000 \mathrm{mg} / \mathrm{l}$ with a discharge by $10 \mathrm{~m}^{3} /$ day to 100 $\mathrm{m}^{3} /$ day. The objective of the research is to obtain organic waste processing equipment that produces processing that meets the threshold value. The research outcomes are as a reference for the industry that requires a representative organic waste treatment unit.

The research is divided into two stages in two years. The first year of the research is semi-aerobic and anaerobic process, then for second year is aerobic process research, semiaerobic process, anaerobic process and aerobic process. The 12 hours HRT process at the first run resulted in a COD concentration of 12,000 $\mathrm{mg} / \mathrm{l}$ to $8,765 \mathrm{mg} / \mathrm{l}$ directly entering an anaerobic I and out 4,640 $\mathrm{mg} / \mathrm{l}$ and entering anaerobic II reactor and exiting with COD 1,380 $m g / l$. Decrease percentage of total COD $(12,000-1,380) \times 100 / 12,000=88.5 \%$. The 18 hours HRT process at the first run resulted in a COD concentration by 12,000 $\mathrm{mg} / \mathrm{l}$ to 8,665 $\mathrm{mg} / \mathrm{l}$ entering the anaerobic reactor I and out 4,125 $\mathrm{mg} / \mathrm{l}$ and entering the anaerobic II and out with COD $965 \mathrm{mg} / \mathrm{l}$. Decrease in total COD (12,000 - 965) x $100 / 12,000=91.95 \%$.

From the experimental stage of semi-aerobic step-screening-anaerobic treatment of two-stage liquid liquor soft drink obtained COD concentration of 12,000 $\mathrm{mg} / \mathrm{l}$ can be reduced concentration to the threshold specified with removal of $88.5 \%-91.95 \%$.
\end{abstract}

Key words: Anaerobic Process, Semi-aerobic Process, Tilted Corrugated Plate Separator (TCPS)

Di Indonesia umumnya dan di Jawa Timur khususnya terdapat industri yang menghasilkan minuman ringan dalam kemasan seperti teh botol, teh gelas, jas-jus, myzone, minuman rasa jeruk, apel, jambu biji, Coca-cola, Fanta, Sprite dan lain lainnya. Pabrik-pabrik ini pada umumnya menghasilkan limbah organik cair yang berkandungan COD cukup tinggi, dari $6.000 \mathrm{mg} / \mathrm{l}$, sampai $15.000 \mathrm{mg} / \mathrm{l}$ dengan debit 10 $\mathrm{m}^{3}$ per hari sampai lebih dari $100 \mathrm{~m}^{3}$ per hari. Kandungan COD didalam limbah berasal dari Glukosa, asam sitrat,dan essence dari jenis minuman yang diproduksi. Pabrik pabrik ini ada yang sudah mempunyai alat pengolah limbah ada juga yang belum mempunyainya. Namun alat pengolahnya limbahnya tidak mampu mengolah beban COD yang tinggi. Bahkan banyak yang mengalami kegagalan dalam pengolahan limbahnya untuk menurunkan kadar COD. Hal ini disebabkan adanya penambahan jenis produk yang menyebabkan limbah dengan konsentrasi COD menjadi tinggi.
Secara teoritis bahwa limbah organik pekat dengan COD lebih dari $3.000 \mathrm{mg} / \mathrm{l}$ sulit diolah dengan pemrosesan secara aerobik, sedangkan proses anaerobik dapat menghasilkan penurunan sampai $95 \%$ pada kadar COD yang sama dan bahkan dapat menghasilkan penurunan COD sampai $80 \%$ untuk limbah yang berkonsentrasi lebih dari $30.000 \mathrm{mg} / \mathrm{l}$ Proses aerobik sulit mereduksi COD sampai $90 \%$ untuk konsentrasi > dari 3.000 mg/l karena kelarutan oksigen molekuler didalam air sangat rendah, $8 \mathrm{mg} / 1$ pada $0^{\circ} \mathrm{C}, 6 \mathrm{ppm}$ pada suhu kamar. Sedangkan proses anaerobik dapat mengolah limbah berkonsentrasi lebih tinggi karena proses ini tidak memerlukan oksigen molekuler.

Pengalaman di lapangan menyatakan bahwa limbah organik telah mengalami fermentasi dalam perjalanan menuju kolam stabilisasi, ini perlu di antisipasi dengan alat pengolahan awal. Hal ini telah dilakukan penelitian sebelumnya yaitu Tyas Yudha, Suwarno, J., (2003), 
Pengolahan Limbah Organik Terlarut Buatan Dengan Reaktor Filter Anaerobik Dua Tahap, mendapatkan bahwa COD 15.000 ppm dapat turun sebesar 70\%,sedangkan COD 10.000 ppm turun sebesar $85 \%$. Selain itu ada penelitian tentang Pengolahan Air Limbah Industri Teh Botol Dengan Teknologi Biologis Anaerobik UASB - Wetland oleh Misbachul Moenir, Sri Moertinah, Sartamtomo (2012) dengan hasil penelitian Hasil penelitian menunjukkan bahwa reaktor UASB I dan II dapat mereduksi COD dengan efisiensi tertinggi $88,51 \%$ dan pengolahan dengan wetland tertinggi $85,02 \%$, Selanjutnya pengolahan air limbah dengan kombinasi UASB dan wetland dapat mereduksi beban cemaran COD antara 97,65 - 98,90\% dan hasil effluen sudah memenuhi baku mutu air limbah industri minuman dalam botol menurut Peraturan Daerah Provinsi Jawa Tengah Nomor 5 Tahun 2012, yaitu COD = $35,44 \mathrm{mg} / \mathrm{l}, \mathrm{TSS}=16 \mathrm{mg} / \mathrm{l}$, dan $\mathrm{BOD}_{5}=13,44$ mg/l. Juga penelitian tentang Studi Penurunan COD dan TSS pada Limbah Cair Industri Minuman Ringan Dengan Menggunakan Teknologi Plasma oleh Amalia Karina, Badrus Zaman dan Abdul Syakur (2012). Dengan hasil penelitian Plasma reaktor dioperasikan dengan tegangan variate $(9 \mathrm{kV}, 10 \mathrm{kV}, 11 \mathrm{kV}$ dan 12 $\mathrm{kV})$ dan jumlah variate sirkulasi (1-7 kali) dengan sistem kontinyu. Sebelum diobati dengan plasma, minuman ringan industri air limbah diangin-anginkan dengan gas oksigen murni terlebih dahulu. Tegangan dan sirkulasi mempengaruhi degradasi COD dan TSS dalam air limbah lunak. Degradasi COD dan TSS meningkat saat kita menerapkan voltase lebih tinggi dan jumlah yang lebih banyak sirkulasi. Degradasi COD dan TSS tertinggi dicapai pada $12 \mathrm{kV}$ dengan 7 sirkulasi. Efisiensi penyisihan COD adalah $94,87 \%$ dan efisiensi penyisihan TSS adalah 95,97\%.

Tujuan kegiatan penelitian dua tahap ini adalah untuk mendapatkan alat pengolahan limbah organik terlarut berkonsentrasi tinggi secara terpadu yang menghasilkan hasil olahan yang memenuhi peraturan Pemerintah untuk dibuang ke perairan umum. Dengan tujuan khusus untuk mengetahui optimalisasi kerja alat-alat pada setiap langkah proses, terutama persen penurunan COD pada setiap langkah proses. Tujuan untuk penelitian tahap pertama adalah untuk mengetahui optimalisasi kerja alat reaktor (fermenter) semiaerobik, alat pemisah endapan, dan reaktor (fermenter) anaerobik dua tahap. Hasil penelitian, yang berupa model, ini diharapkan dapat :

1. Digunakan sebagai referensi untuk industri yang membutuhkan alat pengolahan limbah organik terlarut pekat yang representatif dan juga menunjang kemajuan iptek.

2. Digunakan sebagai referensi pembuatan buku ajar

3. Membuat makalah untuk dipresentasikan di dalam seminar atau dimuat di dalam jurnal terakreditasi

4. Diajukan sebagai Hak Paten.

\section{BAHAN DAN METODE}

Penelitian akan dilaksanakan dalam dua tahap, satu tahap per tahun. Tahun pertama berupa penelitian proses semiaerobik dan proses anaerobik, tahun kedua berupa penelitian proses aerobik, diikuti penelitian terpadu proses semiaerobik, proses anaerobik dan proses aerobik.

\section{Model (Prototype) Pengolahan Terpadu yang Diusulkan.}

Model pengolahan terpadu yang digunakan adalah berupa urutan alat dan proses seperti berikut: 1 Kolam Stabilisasi 2. Fermenter (reaktor) semi-aerobik. 3. Pemisah endapan (Clarifier). 4. Fermenter (reaktor) anaerobik dua tahap, 5. Kolam aerasi. 6 Pemisah endapan. 7. Pengering endapan. Dengan alat seperti model tersebut diharapkan limbah dengan konsentrasi COD $12.000 \mathrm{mg} / \mathrm{l}$ dapat diolah dengan menurunkan COD sampai dibawah $100 \mathrm{mg} / \mathrm{l}$. Didalam reaktor semi-aerobik $\left(\mathrm{NO}_{2}\right)$, limbah akan mengalami proses fermentasi semi-aerobik sehingga terjadi flok-flok bakteri, COD akan berkurang sekitar 30\%. Dari sini limbah dikirim ke alat pemisah flok (tilted corrugated plate Separator $-\mathrm{NO}_{3}$ ). Didalam pemisah flok endapan dipisahkan dan dikirim ke pengering sludge (No.7), sedangkan cairan dialirkan ke reaktor filter anaerobik dua tahap (No.4). Didalam reaktor anaerobik diharapkan terjadi penurunan kandungan bahan organik (COD) sekitar 8090\% dan didalam kolam aerasi diharapkan kandungan COD turun sekitar 90\%. Dari proses 
aerasi, cairan limbah dikirimkan ke alat pemisah endapan biologik (No.6) yang berupa bejana berisi pelat miring (tilted corrugated plate separator). Didalam alat pemisah bahan padat (kumpulan mikroba $=$ sludge biologis) akan terpisah dari cairan (filtrat). Dari alat pemisah endapan, sebagian sludge biologik dikirim kembali ke bak aerasi (reaktor-aerobik), sisanya ke filter pasir (No.7) untuk disaring dan dikeringkan, sedangkan filtrat dialirkan ke bak kontrol yang diberi ikan air tawar dan untuk menguji apakah kandungan COD telah sesuai dengan besaran yang diinginkan. Penelitian akan dilaksanakan dalam 2 (dua) tahap, satu tahap pertahun. Tahap pertama penelitian difokuskan pengolahan secara semi-aerob dan anaerob terutama pengaruh waktu tinggal cairan (Hydraulic Retention Time $=$ HRT $)$ didalam reaktor tehadap penurunan COD, Sedangkan tahap kedua, penelitian diarahkan pada pengolahan secara aerobik terutama pada perbandingan antara feed dengan bakteri, serta proses pemisahan padatan dari cairan dengan alat Tilted Corrugated Plate Separator. Literatur menyatakan bahwa proses anaerobik dapat mencerna limbah organik cair berkonsentrasi setinggi s/d $80.000 \mathrm{mg} / \mathrm{l}$ dengan efisiensi relatif tinggi sampai $90 \%$, sedangkan proses pengolahan secara aerob hanya mampu mengolah limbah dengan konsentrasi bahan organik (COD) sekitar $3.000 \mathrm{mg} / \mathrm{l}$ dengan efisiensi maksimum $90 \%$. Makin kecil konsentrasi akan makin besar efisiensi pengolahan.

Limbah yang akan digunakan adalah limbah tiruan berupa larutan glukosa ditambah sedikit asam sitrat $(\mathrm{pH}=5)$ Larutan yang dibuat tersebut telah di ukur kadar COD-nya dan disesuaikan dengan konsentrasi COD yang di inginkan.

Tujuan penelitian terutama adalah mendapatkan paket/model teknologi pengolahan limbah organik cair berkonsentrasi tinggi secara terpadu dengan cara menguji unjuk kerja alat proses semi aerobik-anaerobik-aerobik. Diharapkan bahwa kandungan COD akan turun dari 12.000 $\mathrm{mg} / \mathrm{l}$ menjadi $80-100 \mathrm{mg} / \mathrm{l}$.

\section{Penelitian Tahap Pertama/Tahun Pertama}

Penelitian skala bench manual dan untuk penelitian tahap pertama (proses semiaerobikanaerobik-aerobik) dengan tujuan pengujian unjuk kerja alat untuk penurunan COD maksimum dilaksanakan sebagai berikut :

1. Persiapan alat dan bahan penelitian dan analisa. Membuat larutan NPK dan $\mathrm{NaOH}$.

2. Membuat larutan limbah tiruan sebanyak 500 liter dengan melarutkan $20 \mathrm{~kg}$ glukosa dan 1000 gram asam sitrat kedalam 500 liter air didalam bak pelarutan, menganalisa COD larutan dan memasukkannya kedalam bak/tangki umpan (Bak No.1) bersama larutan $\mathrm{NaOH}$ sebagai penetral,

3. Memasukkan larutan limbah yang diencerkan $5 \mathrm{x}$ volume larutan, bersama larutan NPK dan $\mathrm{NaOH}$, ke kolom fermentasi (filter) anaerobik (bak No.8 dengan volume 40 liter dan bak No.10 dengan volume 40 liter) dan memasukkan pula bibit mikroba anaerobik dari persediaan. Menunggu sampai timbul gas yang dapat terbakar (sekitar 10-15 hari). Penurunan COD dari keluaran kedua filter anaerobik dipantau ketika gas yang dapat terbakar muncul.

4. Setelah kolom filter anaerobik telah mengeluarkan gas yang dapat terbakar, dimulailah memasukkan larutan glukosa ke bak fermentasi semiaerobik (bak No.6 dengan volume 40 liter), memasukkan mikroba semiaerobik dari persediaan. Menunggu sekitar satu hari untuk perkembangan mikroba menguji kadar COD dari hasil keluaran proses semiaerobik, mengirim keluaran ke bak pemisah endapan (No.7 untuk memisahkan endapan, selanjutnya memulai proses kontinyu dengan memsukan keluaran dari bak No 7 ke kolom filter anaerobik No.8).

5. Proses batch (semi kontinyu, manual) dimulai dengan memasukkan keluaran dari bak No. 7 ke kolom filter anaerobik dengan HRT (Hydraulics Retention Time) yang di variasi sebesar 18 jam, 12 jam dan 6 jam. Konsentrasi COD pada setiap pelaksanaan HRD tertentu dipantau setiap hari. Percobaan untuk setiap HRD akan berlangsung sekitar 1 bulan 
6. Melihat hasil terbaik dari percobaan di No. 5 dan mengkondisikan alat untuk pelaksanaan proses dengan hasil terbaik secara kontinyu (sekitar satu bulan).

7. Melaksanakan percobaan dengan proses kontinyu untuk proses semi aerobikanaerobik. Dengan menggabung proses Pengaliran limbah netral ditambah larutan pupuk NPK, ke bak fermentasi semiaerobik, lalu ke alat pemisah endapan, dilanjutkan ke kolom filter anaerobik I (No. 8) lalu ke penampung keluaran (No. 9), lalu ke kolom filter anaerobik ke-II (No. 10), lalu ke penampung keluaran (No. 10a) dan menunggu untuk proses aerobik dan lain-lainnya.

8. Melaksanakan percobaan dengan proses kontinyu untuk proses semi aerobikanaerobik. Dengan menggabung proses Pengaliran limbah netral ditambah larutan pupuk NPK, ke bak fermentasi semiaerobik, lalu ke alat pemisah endapan, dilanjutkan ke kolom filter anaerobik I (No. 8) lalu ke penampung keluaran (No.9), lalu ke kolom filter anaerobik ke-II (No.10), lalu ke penampung keluaran (No.10a) dan menunggu untuk proses aerobik dan lain-lainnya.

Gambar skema alat untuk peneltian tahap (tahun) pertama adalah seperti gambar berikut :

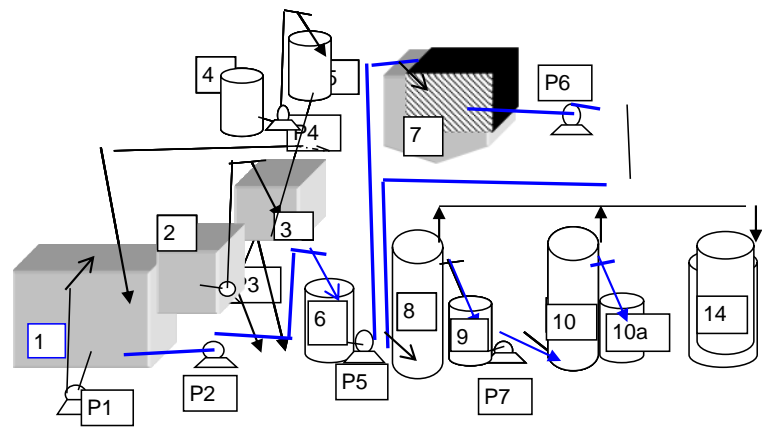

Gambar 1 Skema alat untuk penelitian tahap (tahun) pertama

Keterangan gambar :

1. Kolam stabilisasi

2. Bak pelarutan soda

3. Bak larutan soda

4. Bak pelarutan NPK

5. Bak larutan NPK

6. Fermenter (reactor) semiaerobik

7. Pemisah endapan
8. Fermenter(reactor)anaerobic R1

9. Tandon dari R1

10. Fermenter(reactor) anaerobic $\mathrm{R} 2$

10a.Tandon dari R2

14. Tandon gas bio.

P1. Pompa sirkulasi

P2. Pompa ke bak semiaerobik

P3. Pompa larutan $\mathrm{NaOH}$

P4. Pompa larutan NPK

P5. Pompa keTCPS

P6. Pompa dr TCPS ke R1

P7. Pompa dr B9 ke R2.

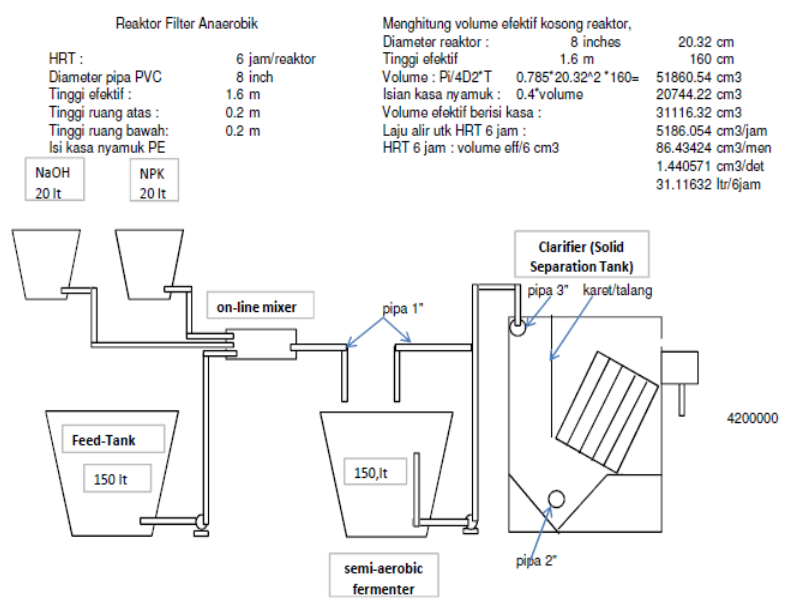

Gambar 2 Reaktor filter anaerobic - clarifier

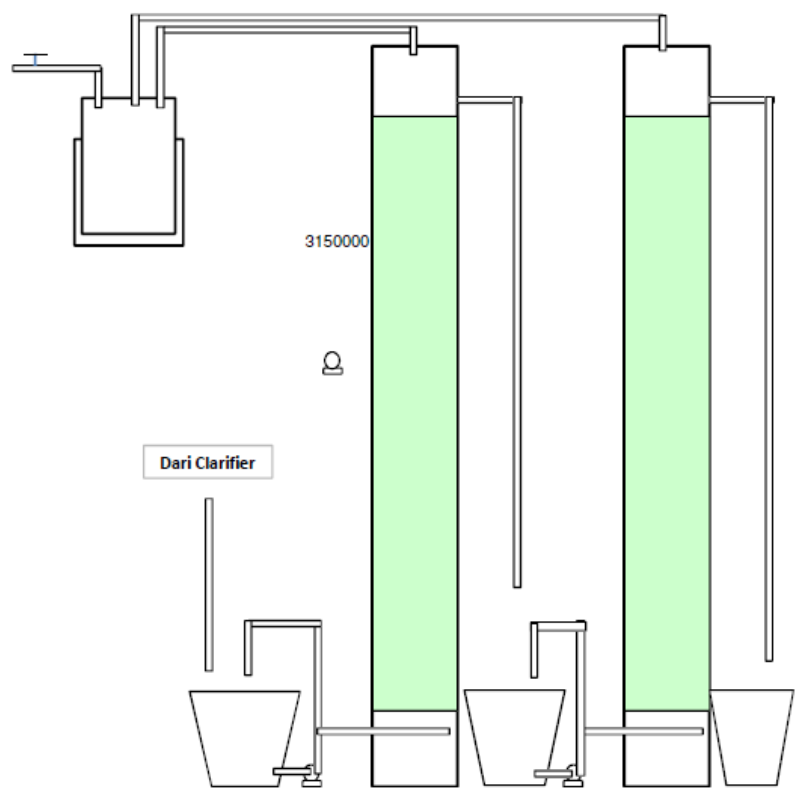

Gambar 3 Reaktor filter anaerobic dua tahap

\section{HASIL}

Hasil percobaan tahap pertama dapat dilihat pada Tabel 1 s/d 3 dibawah ini: 
Tabel 1 adalah hasil 2 percobaan semiaerob di reaktor semiaerob untuk percobaan pertama dan ke dua. Umpan masuk dengan laju alir 6 liter/jam dan konsentrasi COD 12.000 mg/l pengamatan dilaksanakan setiap 4 jam selama 24 jam kontinyu. Dari pecobaan didapatkan bahwa pada percobaan pertama COD turun dari $12.000 \mathrm{mg} / \mathrm{l}$ menjadi $9.010 \mathrm{mg} / \mathrm{l}$ atau $24,92 \%$, sedangkan pada percobaan kedua COD turun dari $12.000 \mathrm{mg} / \mathrm{l}$ menjadi $8410 \mathrm{mg} / \mathrm{l}$ atau 29,92\%. Lalu outlet dari reaktor semiaerobik pertama $9.010 \mathrm{mg} / \mathrm{l}$ COD dimasukkan ke reaktor anaerobik pertama dan keluar dengan kandungan COD $5.850 \mathrm{mg} / \mathrm{l}$ dilanjutkan ke reaktor anaerobik kedua dan keluar dengan kandungan COD $1.980 \mathrm{mg} / \mathrm{l}$. Jadi penurunan COD di reaktor anaerobik 1 dan 2 pada batch pertama adalah $100 \times(9.010-1.980) / 9.010 \%=$ $79,87 \%$. Dan kalau dihitung dari kandungan COD awal, maka penurunan COD nya adalah (12.000-1.980)x100/12.000=83,5\% .

Kandungan COD 1.980 ini sudah dapat di kerjakan dengan proses secara aerobic dengn hasil baik.Selanjutnya hasil pada percobaan semiaerobik kedua dengan kandungan COD sebesar $8.410 \mathrm{mg} / \mathrm{l}$ dimasukkan ke reaktor anaerobik pertama dan keluar dengan COD $5.035 \mathrm{mg} / \mathrm{l}$ dilanjutkan ke reaktor anaerobik ke dua dan keluar dengan kandungan COD sebesar $1.750 \mathrm{mg} / \mathrm{l}$. Jadi penurunan COD di reaktor anaerobik 1 dan 2 pada batch kedua adalah $100 x(8.410-1.750) / 8.410 \%=79,2 \%$. Dan kalau dihitung dari kandungan COD awal, maka penurunan COD nya adalah (12.0001.750) $\times 100 / 12.000=85,41 \%$. Kandungan COD 1.750 ini sudah dapat di kerjakan dengan proses secara aerobic dengan hasil baik.

Tabel 1 Data hasil percobaan semiaerob dengan umpan awal COD $12000 \mathrm{mg} / \mathrm{l}$, laju alir umpan 6 l/jam serta pengamatan setiap 4 jam selama 24 jam untuk percobaan ke 1 dan ke 2

\begin{tabular}{|c|c|c|c|c|c|}
\hline \multicolumn{3}{|c|}{ Percobaan ke -1 } & \multicolumn{3}{|c|}{ Percobaan ke - 2} \\
\hline $\begin{array}{c}\text { Ru } \\
\text { n } \\
\text { ke }\end{array}$ & $\begin{array}{l}\text { Hasil } \\
\text { COD } \\
\text { mg/l }\end{array}$ & $\begin{array}{c}\text { Reduks } \\
\text { i } \\
\text { COD } \%\end{array}$ & $\begin{array}{c}\text { Ru } \\
\mathbf{n} \\
\text { ke }\end{array}$ & $\begin{array}{l}\text { Hasil } \\
\text { COD } \\
\text { mg/l }\end{array}$ & $\begin{array}{c}\text { Reduks } \\
\text { i } \\
\text { COD \% }\end{array}$ \\
\hline $\mathbf{0}$ & 1200 & 0 & 0 & 1200 & 0 \\
\hline 1 & 0 & 15 & 1 & 0 & 15.8333 \\
\hline 2 & 1020 & 22.5 & 2 & 1010 & 3 \\
\hline 3 & 0 & 24.1666 & 3 & 0 & 22.5 \\
\hline 4 & 9300 & 7 & 4 & 9300 & 29.5833 \\
\hline 5 & 9100 & 24.5833 & 5 & 8450 & 3 \\
\hline 6 & 9050 & 3 & 6 & 8400 & 30 \\
\hline & 9010 & 24.9166 & & 8410 & 29.9166 \\
\hline & 9010 & 7 & & 8410 & 7 \\
\hline & & 24.9166 & & & 29.9166 \\
\hline & & 7 & & & 7 \\
\hline
\end{tabular}


Tabel 3 Data hasil pengamatan di Reaktor anaerobik pertama dan kedua, umpan awal COD $9.010 \mathrm{mg} / \mathrm{l}$, Volume efektif reaktor 40 liter, HRT 6 jam dan laju alir 6 liter/jam Pengamatan setiap 24 jam, setelah aliran mantap

Reaktor Anaerobik1

Reaktor Anaerobik 2

\begin{tabular}{cccccccc}
\hline Run ke & Input ke R1 & Output dr R1 & $\begin{array}{c}\text { Reduksi COD } \\
(\mathbf{\%})\end{array}$ & Run ke & Input ke R2 & $\begin{array}{c}\text { Output dr } \\
\text { R2 }\end{array}$ & $\begin{array}{c}\text { Reduksi COD } \\
(\%)\end{array}$ \\
$\mathbf{0}$ & 9010 & 5850 & 35.07214 & 0 & & & \\
$\mathbf{1}$ & 9010 & 5860 & 34.96115 & 1 & 5860 & 1990 & 66.04096 \\
$\mathbf{2}$ & 9010 & 5855 & 35.01665 & 2 & 5855 & 1990 & 66.01196 \\
$\mathbf{3}$ & 9010 & 5850 & 35.07214 & 3 & 5850 & 1990 & 65.98291 \\
$\mathbf{4}$ & 9010 & 5845 & 35.12764 & 4 & 5845 & 1992 & 65.91959 \\
$\mathbf{5}$ & 9010 & 5840 & 35.18313 & 5 & 5840 & 1986 & 65.99315 \\
$\mathbf{6}$ & 9010 & 5845 & 35.12764 & 6 & 5845 & 1986 & 66.02224 \\
$\mathbf{7}$ & 9010 & 5850 & 35.07214 & 7 & 5850 & 1985 & 66.06838 \\
$\mathbf{8}$ & 9010 & 5855 & 35.01665 & 8 & 5855 & 1985 & 66.09735 \\
$\mathbf{9}$ & 9010 & 5850 & 35.07214 & 9 & 5850 & 1984 & 66.08547 \\
$\mathbf{1 0}$ & 9010 & 5855 & 35.01665 & 10 & 5855 & 1980 & 66.18275 \\
$\mathbf{1 1}$ & 9010 & 5860 & 34.96115 & 11 & 5860 & 1980 & 66.2116 \\
$\mathbf{1 2}$ & 9010 & 5850 & 34.90115 & 12 & 5850 & 1980 & 66.15385 \\
Jumlah & & $\mathbf{7 6 0 6 5}$ & & Jumlah & & $\mathbf{2 3 8 2 8}$ &
\end{tabular}

Tabel 2 Data hasil pengamatan di Reaktor anaerobik pertama dan kedua, umpan awal COD $8410 \mathrm{mg} / \mathrm{l}$, Volume efektif reaktor 40 lt, HRT 6 jam dan laju alir 6 lt/jam (HRT 6 jam) Pengamatan setiap 24 jam, setelahaliran mantap

\begin{tabular}{|c|c|c|c|c|c|c|c|}
\hline \multicolumn{4}{|c|}{ Reaktor Anaerobik 1} & \multicolumn{4}{|c|}{ Reaktor anaerobik 2} \\
\hline \multirow[t]{2}{*}{ Run ke } & Input ke & Output dr & Reduksi & Run ke & Input ke & Output dr & Reduksi \\
\hline & $\mathbf{R 1}$ & $\mathbf{R 1}$ & COD, \% & & $\mathbf{R 2}$ & $\mathbf{R 2}$ & COD, \% \\
\hline $\mathbf{0}$ & 8410 & & & 0 & & & \\
\hline 1 & 8410 & 5050 & 39.95244 & 1 & 5050 & 1764 & 65.06931 \\
\hline 2 & 8410 & 5050 & 39.95244 & 2 & 5050 & 1765 & 65.0495 \\
\hline 3 & 8410 & 5045 & 40.01189 & 3 & 5045 & 1765 & 65.01487 \\
\hline 4 & 8410 & 5045 & 40.01189 & 4 & 4045 & 1765 & 56.36588 \\
\hline 5 & 8410 & 5045 & 40.01189 & 5 & 5045 & 1760 & 65.11397 \\
\hline 6 & 8410 & 5040 & 40.07134 & 6 & 5040 & 1760 & 65.07937 \\
\hline 7 & 8410 & 5040 & 40.07134 & 7 & 5040 & 1760 & 65.07937 \\
\hline 8 & 8410 & 5045 & 40.01189 & 8 & 5045 & 1755 & 65.21308 \\
\hline 9 & 8410 & 5040 & 40.07134 & 9 & 5040 & 1755 & 65.17857 \\
\hline 10 & 8410 & 5035 & 40.1308 & 10 & 5035 & 1755 & 65.14399 \\
\hline 11 & 8410 & 5035 & 40.1308 & 11 & 5035 & 1755 & 65.14399 \\
\hline \multirow[t]{2}{*}{12} & 8410 & 5035 & 40.1308 & 12 & 5035 & 1750 & 65.2433 \\
\hline & Jumlah & 60505 & & & nlah & 21109 & \\
\hline \multicolumn{2}{|c|}{ Hasil COD rata-rata } & 5042.083 & & Hasil CO & a2 di R2 & 1759.083 & \\
\hline \multicolumn{2}{|c|}{ Reduksi di R1 } & 40.04657 & & Reduksi & & 65.16667 & \\
\hline
\end{tabular}




\section{PEMBAHASAN}

Hasil pengolahan secara semiaerobikanaerobik untuk HRT 12 jam dan HRT 18 jam adalah sebagai berikut :

\section{Proses dengan HRT 12 jam}

HRT 12 jam, umpan masuk reactor semiaerobik $12.000 \mathrm{mg} / \mathrm{l}$, keluar $8.765 \mathrm{mg} / \mathrm{l}$ langsung masuk reaktor anaerobik I dan keluar $4.640 \mathrm{mg} / \mathrm{l} \mathrm{lalu}$ masuk reaktor anaerobik II dan keluar dengan COD $1.380 \mathrm{mg} / \mathrm{l}$. Penurunan COD total (12.000-1.380)x100/12.000=88,5 \%. Hasil bisa diproses di proses aerobik lanjutan dengan hasil baik.

HRT 12 jam (run kedua), umpan masuk reaktor semiaerobik $12.000 \mathrm{mg} / \mathrm{l}$, keluar $8.180 \mathrm{mg} / \mathrm{l}$ langsung masuk reaktor anaerobik I dan keluar $3.840 \mathrm{mg} / \mathrm{l}$ lalu masuk reaktor anaerobik II dan keluar degan COD $1.140 \mathrm{mg} / \mathrm{l}$ Penurunan COD total $(12.000-1.140) \times 100 / 12.000=90,5 \%$. Hasil bisa diproses di proses aerobik lanjutan dengan hasil baik.

\section{Proses dengan HRT 18 jam}

HRT 18 jam, umpan masuk reaktor semiaerobik $12.000 \mathrm{mg} / \mathrm{l}$, keluar $8.665 \mathrm{mg} / \mathrm{l}$ langsung masuk reaktor anaerobik I dan keluar $4.125 \mathrm{mg} / \mathrm{l}$ lalu masuk reaktor anaerobik II dan keluar dengan COD $965 \mathrm{mg} / \mathrm{l}$. Penurunan COD total (12.000$965) \times 100 / 12.000=91,95 \%$. Hasil bisa diproses di proses aerobik lanjutan dengan hasil baik.

HRT 12 jam (run kedua), umpan masuk reaktor semiaerobik $12.000 \mathrm{mg} / \mathrm{l}$, keluar 8.080 $\mathrm{mg} / \mathrm{l}$ langsung masuk reaktor anaerobik I dan keluar $3.735 \mathrm{mg} / \mathrm{l}$ lalu masuk reaktor anaerobik II dan keluar dengan COD $855 \mathrm{mg} / \mathrm{l}$ Penurunan COD total $(12.000-855) \times 100 / 12.000=92,88 \%$. Hasil bisa diproses di proses aerobik lanjutan dengan hasil baik.

\section{SIMPULAN}

Dari hasil percobaan pengolahan tahapan semiaerobik-penyaringan-anaerobik dua tahap telah berhasil dilaksanakan dengan hasil bahwa limbah cair minuman ringan dalam kemasan dengan konsentrasi COD $12.000 \mathrm{mg} / \mathrm{l}$ dapat diturunkan konsentrasinya hingga ambang batas yang ditentukan. Pengolahan dengan HRT 18 jam merupakan pengolahan dengan hasil penurunan COD paling besar.

\section{UCAPAN TERIMAKASIH}

Terima kasih kepada Profesor H. Ir. Judjono Suwarno atas saran-saran pada penelitian ini demi untuk menghasilkan karya ilmiah yang baik.

\section{DAFTAR PUSTAKA}

Karina A. Zaman B. Syakur A., 2012, Studi Penurunan COD dan TSS Pada Limbah Cair Industri Minuman Ringan Dengan Menggunakan Teknologi Plasma (Studi Kasus PT. Coca Cola Amatil Indonesia Semarang)

Moenir.M\&Moertinah S. 2012, Pengolahan Air Limbah Industri Teh Botol Dengan Teknologi Biologis Anaerobik UASB Wetland

Suwarno J., 1993, Pengolahan Limbah Pabrik Alcohol dengan Filter Anaerobic Dua Tahap,

Laporan penelitian, LPPM ITS.

Suwarno J., 1994, Pengolahan Limbah Pabrik Tahu dengan Cara Aerobic , Laporan Penelitian, LPPM ITS.

Suwarno. J, 1994, Pengolahan Limbah Pabrik Tahu dengan Filter Anaerobic Dua Tahap,Laporan penelitian, LPPM ITS.

Russel D.L., 2006, Practical Wastewater Treatment, John Willey \& Sons, Inc., Hoboken, New Jersey, USA.

Tchobanoglous,G.Franklin L.Burton, H.David Stensel ,2004, " Wastewater Engineering", McGraw-Hill, New York 